\title{
Monthly Average Rainfall Forecasting Based On An Adaptive Neuro-Fuzzy Inference System in Upper Brahmani Basin, Odisha, India
}

\section{M.Uma Maheswar Rao ( $\sim$ Mahesh93.happy@gmail.com )}

NIT Rourkela: National Institute of Technology Rourkela https://orcid.org/0000-0003-0889-091X

Kanhu Charan Patra

National Institute of Technology Rourkela

Suvendu Kumar Sasmal

National Institute of Technology Rourkela

\section{Research Article}

Keywords: Flood, Rainfall Forecasting, Upper Brahmani Basin, ANFIS

Posted Date: January 6th, 2022

DOI: https://doi.org/10.21203/rs.3.rs-1213433/v1

License: (c) (i) This work is licensed under a Creative Commons Attribution 4.0 International License.

Read Full License 


\section{Abstract}

Floods disrupt human activities, resulting in the loss of lives and property of a region. Excessive rainfall is one of the reasons for flooding, especially in the downstream areas of a catchment. Because of its complexity, understanding and forecasting rainfall is incredibly a challenge. This study investigates the use of an Adaptive Neuro-Fuzzy Inference System (ANFIS) in predicting rainfall using several surface weather parameters as predictors. An ANFIS model is developed for forecasting rainfall over the Upper Brahmani Basin by using 30 years of climate data. A hybrid model with six membership functions gives the best forecast for an area. The suggested method blends neural network learning capabilities with language representations of fuzzy systems that are transparent. The application of ANFIS is to the upper Brahmani river basin is tried for the first time. The ANFIS model with various input structures and membership functions has been built, trained, and tested to evaluate the capability of the model. Statistical performance indices are used to evaluate the performance. Using the developed model, forecast is done for year $2021-2030$.

\section{Introduction}

Rainfall forecasting is vital for the design, planning, and development of water resource management strategies. It aids in determining the water balance between future supply and availability, ensuring efficient water resource organizational strategies(Rasel and Imteaz 2016). Due to its importance in sustainable flood control, agricultural activities, and ecological management, rainfall is the single most significant hydro-climate parameter amongst the rest. As a result, for many decades, one of the key aims of water resource managers has been to predict the anticipated rainfall over several months or seasons(Del Real et al. 2020). (Calp 2019) Using various linear and non-linear techniques, several researchers have attempted to establish correlations between large-scale climate factors and rainfall in various areas of the world. Soft computing techniques including Artificial Neural Networks (ANN), Support Vectors Regression (SVR), and Neuro-fuzzy System (NFS) have been increasingly used in hydrology and water resource modeling in recent years(Emamgholizadeh et al. 2014)(Bacanli et al. 2009). Weather forecasting is an imperious and demanding task that is carried out by various water resource researchers for water resource management. Due to the nature of producing uncertain judgments, this specific objective in this domain is a big challenge. Rainfall is a random variable whose frequency is influenced by several determinants such as the surface temperatures on daily to seasonal time scales, surface pressure on daily to longer than weekly time scales, relative humidity, wind speed at different elevations, solar radiation, and other atmospheric variables time scales at the location(Aldrian and Djami 2010). Weather predictions are necessary for forecasting the weather for the future. Weather forecasting utilizes several methodologies, starting from basic sky observation to incredibly complicated computational mathematical models(Tektas 2010). Among the scientific study works on weather forecasting, there are a few that should be highlighted. (Zhang et al. 2016)(Zhang et al. 2020) was the first to implement ANN, a key Soft Computing approach for weather forecasting. In the prediction of atmospheric data, fuzzy logic is found to be quite useful. 
Indian economy is closely related to water management, which includes the stack holders of agriculture, domestic and household water supply, power generation, industry, fisheries, environment, transportation, and other sectors. Under initial water availability situations, it should ideally balance the water supply and water demand(Nourani and Komasi 2013). The activity of maximizing the use of available water resources via planning, development, distribution, and management is the key which firmly depends on rainfall over the area. The term "Neuro-fuzzy" refers to a hybrid artificial intelligence method that combines fuzzy logic with artificial neural networks. In the literature several neuro-fuzzy systems have been proposed(Emamgholizadeh et al. 2014)(Tektas 2010). The ANFIS model has been proposed for modelling hydrological time series, developing a rainfall distribution forecasting model in Victoria, southern Australia, anticipating floods, and making spatial flood predictions, such as using the ANFIS to predict zenith tropospheric delays (ZTD) instead of GPS-derived ZTD to estimate atmospheric water content (Aftab et al. 2018)(Kyada et al. 2018). Artificial neural networks (ANNs) have previously been widely utilized to simulate rainfall forecasts, especially when paired with a linear multiple-input singleoutput (MISO) model for daily rainfall-runoff modeling(Usha and Priya 2016)(Rasel and Imteaz 2016).

Based on previous research ANFIS is found to be an effective tool for rainfall modeling, and using ANFIS network exploration prediction of rainfall for the catchment is more accurate. Forecasting appears to involve estimating the future values based on historical values in a time series.

\section{Study Area And Data Collection}

Brahmani River Basin is located in the Indian peninsula's states of Chhattisgarh (Novitasari et al. 2020), Jharkhand, and Orissa, from latitudes $20^{\circ} 28^{\prime}$ to $23^{\circ} 35^{\prime} \mathrm{N}$ and longitudes $83^{\circ} 52^{\prime}$ to $87^{\circ} 30^{\prime} \mathrm{E}$ (Figure -1 ). It lies between the Mahanadi Basin on the right and the Baitarani Basin on the left. Brahmani is the secondlargest river system in Orissa. Two major tributaries viz. the Sank and Koel join together at Vedvyas near Rourkela, Odisha, and the river system is named Brahmani hereafter. Due to its location close to the Bay of Bengal, Odisha is a natural disaster porn state in India. About $57.34 \%$ of the catchment of the basin area out of the total $22,576 \mathrm{Sq} . \mathrm{Km}$.

This study attempts to take into account the catchment intercepting up to the Rengali Dam, which covers 17504 square kilometers in the upper section of the Brahmani river basin as shown in figure1.

\subsection{Climatic Parameters}

More than $70 \%$ of India's population is fully dependent on agriculture. A majority of the cultivable area relies on precipitation as its principal source of water. As a result, precipitation schedule and magnitude are crucial factors that affect the country's economy (Nourani and Komasi 2013). Climate change has a significant impact on our daily lives. We have been preoccupied with climate shifts from the dawn of human history. Temperature, wind speed, solar radiation, and relative humidity are the climatic parameters used in the studies to predict anticipated rainfall. The period of data, units, sources, and spatial resolutions are given in Table 1. IMDAA (Indian Monsoon Data Assimilation and Analysis) is a 
national atmospheric reanalysis that spans the Indian subcontinent (Indirarani et al. 2021). The IMDAA is the outcome of a partnership between the United Kingdom's Met Office (MO), India's National Centre for Medium-Range Weather Forecasting (NCMRWF), and the India Meteorological Department (IMD).

Table 1

Input Data Set for ANFIS Model to Evaluate Future Rainfall Data

\begin{tabular}{|lllllll|}
\hline Parameters & Rainfall & $\mathbf{T}_{\max }$ & $\mathbf{T}_{\min }$ & $\mathbf{R H}$ & WS & $\mathbf{S R}$ \\
\hline Unit & $\mathrm{mm} /$ Day & ${ }^{\circ} \mathrm{C}$ & ${ }^{\circ} \mathrm{C}$ & $\%$ & $\mathrm{~m} / \mathrm{s}$ & $\mathrm{kW}-\mathrm{hr} / \mathrm{m}^{2} / \mathrm{day}$ \\
\hline Frequency & Daily & & & & & \\
\hline Time Period & $1983-2020$ & & & & \\
\hline Source & Indian Monsoon Data Assimilation and Analysis Reanalysis (IMDAA) \\
\hline Spatial Resolution & $0.25 \times 0.25$ & & & & \\
\hline
\end{tabular}

\section{Methodology}

ANFIS uses both artificial fuzzy logic and a neural inference system. It has a hybrid approach to estimate the variables, least-square to evaluate the linear variable, and an inaccuracy backpropagation algorithm to estimate dynamical parameters (Kişi 2006). ANFIS is comprised of five levels. The linear parameter is estimated in the first layer(Calp 2019). The idea of fuzzy sets, in which there is no sharp or obvious border, underpins fuzzy logic. Which is multi-valued and deals with degrees of membership and truth, unlike two-valued Boolean logic. In fuzzy logic, a membership value is any logical value from the set of real numbers between 0 (totally false) and 1 (entirely true), and the function that encodes such values is called a membership function. Artificial neural networks' learning ability and relational structure are integrated with fuzzy logic's decision-making process in ANFIS. As with artificial neural networks, ANFIS achieves learning with samples using a train data set. As a result, the most optimal ANFIS structure for solving the associated problem is obtained. The acquired structure is put to the test to see how it reacts to materials it has never seen before (Rao et al. 2020). Membership functions are available in a multitude of shapes, including triangular, trapezoidal, Gaussian, sigmoidal, and so on, and are chosen depending upon the application. Fuzzy logic contains its own set of logical operators, such as AND, OR, NOT, and others (Mekanik et al. 2016). Based on the membership value idea, each of these operations has its meaning. The other key components of fuzzy logic are fuzzy rules, which connect the fuzzy sets. If the rule is correct and the antecedent is correct, the consequent must also be correct, following the IF-THEN rule. As shown in Figure 2, the four phases of a typical fuzzy inference system (FIS) are as follows. (a) Fuzzification of input variables, (b) evaluation of each rule's output, (c) aggregation of several rules' outputs, and (d) defuzzification, which converts fuzzy results into crisp output. The Takagi-Sugeno FIS is one of the most often used FIS types(Ashrafi et al. 2017)(Nourani and Komasi 2013). A fuzzy rule in the Takagi-Sugeno FIS is mostly composed of a linear transformation of crisp inputs rather than fuzzy rules. A typical Takagi-Sugeno FIS rule set contains two fuzzies "IF-THEN" rules. 
The following is a representation of a first-order Sugeno fuzzy model (Jang 1993) that has two inputs ( $x$ and $y$ ) and one output (f), as well as Takagi and Sugeno's two fuzzy IF-THEN rules.

$$
R U L E-1: \text { ifxis }_{1} \text { andyis }_{1} \text { thenf }_{1}=p_{1} x+q_{1} y+r_{1}
$$

1

$$
R U L E-2: \text { ifxis }_{1} \text { andyis }_{1} \text { thenf }_{1}=p_{1} x+q_{1} y+r_{1}
$$

2

If the premise parameters are $\left(p_{i}, q_{i}, r_{i}\right)$, the user defines the premise parameters, which must be optimized using the ANFIS training method.

In a fuzzy system with two membership functions, the $A_{1}$ and $A_{2}$ represent input $x$ membership functions, while the $B_{1}$ and $B_{2}$ represent input $y$ membership functions. Figure 3 shows the ANFIS architecture, which has two input parameters $(x, y)$ and one output parameter $(f)$. It's worth noting that each layer's nodes have the same functions, which are described in the sections below. The output of the layer $\mathrm{i}^{\text {th }}$ node is represented by the $O_{l, i}$.

LAYER 1: Each node I in this layer is an adaptive node, with the following node function

$$
O_{1, i}=\mu A_{i}(x) \text { fori }=1,2
$$

3

$$
O_{1, i}=\mu B_{i-2}(y) \text { fori }=1,2
$$

4

Where $\mathrm{x}$ or $\mathrm{y}$ are the noes representing input variables for $\mathrm{I}$ and $\mathrm{A}_{\mathrm{i}}$ or $\mathrm{B}_{\mathrm{i}-2}$ is a linguistic label (small or large). In other words, $O_{1, i}$ specifies the extent to which the provided input $x$ or $y$ meets the quantifier and the membership grade of a fuzzy set $A$ and $B\left(A_{1}, A_{2}, B_{1}\right.$, or $B_{2} A$ s $A^{\prime}$ s membership function, any appropriate parameterized membership function can be used, including triangular, trapezoidal, Bell, Gaussian, and other forms. This research makes use of a generalized bell-shaped membership function.

LAYER 2: Each node in this layer is a circular junction, and the layer's output is generated using equation 5 as the product of all incoming signals.

$$
O_{2, i}=\mathrm{W}=\mu A_{i}(x) \mu B_{i}(y), i=1,2
$$

5

The rule's firing strength is represented by each node output, indicating that this layer determines the rule's strength. 
LAYER 3: Each node decides is a fixed cluster which calculates the following ratio of each $i^{\text {th }}$ rule's firing strength to the total of all rule firing strengths

$$
o_{3, i}=\bar{W}_{i} f_{i}=\frac{W_{i}}{W_{1}+W_{2}}, i=1,2
$$

6

LAYER 4: The nodes in this layer are all adaptable, having the function;

$$
O_{3, i}=\bar{W}_{i} f_{i}=\bar{W}_{i}\left(p_{i} x+q_{i} y+r_{i}\right) \text { fori }=1,2
$$

7

The succeeding parameters of this layer are pi, qi, and ri, whereas $\bar{W}_{i}$ is the normalized firing strength generated from layer 3 . These parameters show optimum values after the ANFIS learning algorithm.

LAYER 5: This is the final layer, which contains only one circular node that accumulates all of the incoming signals from layer 4 to determine the overall output which gives is ;

$$
\text { Overalloutput }=O_{5,1}=f=\sum \bar{\omega}_{i} f_{i}=\frac{\sum_{i} \omega_{i} f_{i}}{\sum_{i} \omega_{i}}
$$

8

Only the adaptive nodes may be altered based on the user's requirements. All circular nodes are fixed, whereas square nodes are flexible.

The ANFIS method, which employs the Tagaki-Sugeno-Kang (TSK) first-order model, is used here to estimate the rainfall. A hybrid learning algorithm is chosen as a rainfall forecast among the numerous types of supervised learning algorithms. The fact that a multi - task learning algorithm has been widely utilized is a good argument to employ it (Suparta and Samah 2020)(Mosavi et al. 2018)(Sharma and Goyal 2017)(Sai Tarun et al. 2019). One of the benefits of ANFIS is that it mixes ANN and fuzzy systems, generating fuzzy if-then rules with proper membership functions that may learn anything from the imprecise data input and lead to an inference utilizing ANN learning skills. Another advantage is that it can make excellent use of the self-learning capabilities of neural networks and memory capacities, resulting in a more stable training process.

For system identification, fuzzy logic and artificial networks are complementary rather than antagonistic, making their use jointly desirable. In 1993 (Jang 1993)(Karaboga and Kaya 2019) developed the ANFIS by combining these two soft-computing tools and building a Sugeno-type fuzzy inference system to transcend the individual limits of ANN and fuzzy logic (FIS). The ANFIS is an adaptive neuro-fuzzy inference system that combines the recognition and adaption capabilities of an ANN with the decisionmaking capabilities of a fuzzy logic system. As a result, the ANFIS overcomes the shortcomings of the 
ANN and FIS techniques and provides a trustworthy system identification method, particularly when the input-output link is complicated. In the ANFIS, a fuzzy model is created first using rules derived from the system's input and output data, and then the neural network is used to fine-tune the fuzzy model's rules to create the best ANFIS model. Seventy-five percent of the data is set aside for training and twenty-five percent for testing. The system's output is checked to see if it matches the given target it was given. If this is not the case, a new network design or learning approach is introduced to improve the learning method. The RMSE (Root Mean Squared Error) is used for testing. If RSME is small enough, ANFIS is considered to have effectively finished the training process.

\section{Development Of Anfis Univariate Time Series Forecasting Model}

Three-time series inputs $\mathrm{R}(\mathrm{t}), \mathrm{R}(\mathrm{t}-1)$, and $\mathrm{R}(\mathrm{t}-2)$ and one output $\mathrm{R}(\mathrm{t}+1)$ compensate for the ANFIS architecture used in this study. The inputs are average monthly rainfall data, which the ANFIS model uses to forecast monthly rainfall. the ANFIS framework is designed as a three-layered model with input, output, and hidden layers. For the rainfall prediction technique, the hidden layer is employed with Gaussian membership functions. The prediction model's input-output structure may be expressed using the equation given as.

$$
\text { Input: } W(t)=[R(t), R(t-1), R(t-2)]
$$

9

$$
\text { Output: } s(t)=[R(t+1)]
$$

10

Where $\mathrm{R}(\mathrm{t})$ denotes the forecasted data, $\mathrm{R}(\mathrm{t}), \mathrm{R}(\mathrm{t}-1)$ and $\mathrm{R}(\mathrm{t}-2)$ denote previous periods. The data (both inputs and output) for training and testing, is normalized in the range of $[-1,1]$ using equation 11 .

$$
R_{\text {norm }}=2 \times\left[\frac{R-R_{\min }}{R_{\max }-R_{\min }}\right]-1
$$

11

where $R_{n o r m}=$ Normalized value of data, $R_{\max }=$ Maximum value of data and $R_{\min }=$ Minimum value of data

The present ANFIS model uses "Gaussian" membership functions (MF) with MF type "Constant". It is to be noted that the Grid partition technique is used here to figure out the number of MFs. The number of MFs is $2^{3}=8$. The ANFIS structure is shown in Figure 4. All together 100 epochs are found to be sufficient for obtaining a constant value of Error (Figure 5).

\section{Results And Discussion}


In this section, the details of the developed model are discussed along with the parametric analysis.

\subsection{Evaluation of Model performance}

The evaluation of the performance of input parameters is carried out by developing and training ANFIS models based on each input parameter. The input parameters having the greatest influence on the output are found out, for using it ineffectively anticipating the output. Statistical indicators such as root mean square error (RMSE) and coefficient of determination $\mathrm{R}^{2}$ can be used to safeguard this evaluation. Tables 2 and 3 include the details of the membership functions and constants, respectively.

Table 2

Parameters of gbel membership functions

\begin{tabular}{|c|c|c|c|c|}
\hline \multirow[t]{3}{*}{ Inputs } & \multicolumn{4}{|c|}{ Membership functions } \\
\hline & \multicolumn{2}{|l|}{ MF1 } & \multicolumn{2}{|l|}{ MF2 } \\
\hline & $\sigma$ & c & $\sigma$ & c \\
\hline$I_{1}$ & 0.2152 & -1.031 & 0.2323 & -0.6165 \\
\hline$I_{2}$ & 0.08962 & -1.032 & 0.1304 & -0.7043 \\
\hline$I_{3}$ & 0.2201 & -1.024 & 0.2318 & -0.6137 \\
\hline
\end{tabular}

Table 3

List of constants

\begin{tabular}{|ll|}
\hline Membership Functions & Constants \\
\hline 1 & -1.084 \\
\hline 2 & -0.783 \\
\hline 3 & -1.099 \\
\hline 4 & -0.6866 \\
\hline 5 & -0.8932 \\
\hline 6 & -0.9446 \\
\hline 7 & -0.5058 \\
\hline 8 & -0.9508 \\
\hline
\end{tabular}

Figures 6 and 7 show the regression plots for training and testing data, respectively. It is found that the forecasting model has very good generalization performance due to its ability to predict the testing data reasonably. The error distribution is shown in Figure 8 . It is found that the peak of the normal distribution curve is very close to zero in both training and testing data sets. 
The developed model is used to forecast for 2011-2020 and the outcomes are compared with the actual data as shown in Figure 9. The anticipated data appear to be in good accord with the actual data.

\subsection{Parametric analysis}

Variations of MFs for each input parameter are shown in Figures 10,11, and 12. The surface plots are shown in Figures 13,14, and 15. The surface plot explains the combined effect of the influencing parameters. While drawing the surface plot two parameters are varying within their highest and lowest range while the remaining other parameter is assigned the value of its median.

\subsection{Development of Empirical Expression}

Step1: Normalization of input

For a set of inputs i.e. $\left[I_{1}, I_{2}, I_{3}\right]$ within the considered range, the normalization is done using Equation 12. The normalized input set becomes $\left[I_{1 n}, I_{2 n}, I_{3 n}\right]$.

$R_{\text {norm }}=2 \times\left(\frac{R-R_{\min }}{R_{\max }-R_{\min }}\right)-1$

Where, $R_{\text {norm }}=$ normalized value of data, $R_{\max }=$ maximum value of data and $R_{\min }=$ minimum value of data

Step2: Calculation of firing strength of ANFIS rules

In the present model, eight rules are present, which are represented by $W_{1}-W_{8}$, Where

$W_{1}=\left[I_{1} M F_{1}\right] \times\left[I_{2} M F_{1}\right] \times\left[I_{3} M F_{1}\right]$

$W_{2}=\left[I_{1} M F_{1}\right] \times\left[I_{2} M F_{1}\right] \times\left[I_{3} M F_{2}\right]$

$W_{3}=\left[I_{1} M F_{1}\right] \times\left[I_{2} M F_{2}\right] \times\left[I_{3} M F_{1}\right]$

$W_{4}=\left[I_{1} M F_{1}\right] \times\left[I_{2} M F_{2}\right] \times\left[I_{3} M F_{2}\right]$

$W_{5}=\left[I_{1} M F_{2}\right] \times\left[I_{2} M F_{1}\right] \times\left[I_{3} M F_{1}\right]$

$W_{6}=\left[I_{1} M F_{2}\right] \times\left[I_{2} M F_{1}\right] \times\left[I_{3} M F_{2}\right]$

$W_{7}=\left[I_{1} M F_{2}\right] \times\left[I_{2} M F_{2}\right] \times\left[I_{3} M F_{1}\right]$

$W_{8}=\left[I_{1} M F_{1}\right] \times\left[I_{2} M F_{2}\right] \times\left[I_{3} M F_{2}\right]$

In the above expressions, $I_{i} M F_{j}$ corresponds to $\mathrm{i}^{\text {th }}$ input and $\mathrm{j}^{\text {th }} \mathrm{MF}$. The Gaussian membership function is represented by equation 13 . 
$I_{i} M F_{i}=e^{\frac{-(x-c)^{2}}{2 \sigma^{2}}}$

Step 3: Calculation of normalized output

$$
O_{n}=\frac{\left(W_{1} \times Z_{1}\right)+\left(W_{2} \times Z_{2}\right)+\ldots \ldots+\left(W_{8} \times Z_{8}\right)}{W_{1}+W_{2}+\ldots . .+W_{8}}
$$

Where;

$-1 \leq O_{n} \leq 1$

Step 4: De-normalization of $O_{n}$

$O=\left[0.5 \times\left(O_{n}+1\right) \times\left(O_{\max }-O_{\min }\right)\right]+O_{\min }(15)$

The Upper Brahmani basin's future rainfall can be projected by following the above step-by-step strategy. The assumption in the present study is that the observed prediction will follow the nearly same trend over the upcoming years and that the change in land use and land cover will not have to vary much.

\subsection{Forecasting by using Developed Empirical Equation for 2021-2030}

As shown in figure 9, a constructed empirical equation predicts monthly rainfall, which yields acceptable results. Monthly rainfall is expected from 2021 to 2030 using the derived equation, as shown in figure 16 . The established empirical equation offers excellent results for the upper Brahmani river basin, as seen in the graph below. The variations in June - August are attributed to irregular monsoon climate. But these variations are in acceptable limit. Moreover, the highest rainfall is forecasted for June- August, which is the striking characteristic of monsoon climate. Hence the present model can be used to forecast the rainfall with reasonable accuracy.

\section{Conclusion}

In the present study, a regional analysis is performed to develop a forecasting model for the upper Brahmani river basin, Odisha, India. Real-time weather data of the past four decades are used to create a model that is based on fuzzy algorithms. Using the trained fuzzy model based on the univariate forecasting model and the sensitivity study, the following major inferences are drawn;

a) Gaussian Membership Function with the hybrid algorithm can predict monthly average rainfall with satisfactory accuracy as the $\mathrm{R}$ values for training and testing are found to be 0.90 and 0.87 respectively.

b) The comparison of model forecast results with the actual result for the year 2011-2020 indicates the forecasting ability of the present model for future rainfall. 
c) An empirical expression is developed in the form of Equation 15 to forecast future rainfall, provided the previous three months' rainfall data is known.

d) Sensitivity analysis indicates that rainfall before the previous two months is an important parameter to forecast average monthly rainfall. This trend is in good agreement with climatic conditions of subtropical regions where seasonal variation is less.

e) The average rainfall forecasted by the present model can be implemented towards the future design of water resource structures as the design parameters can be ascertained by using the rainfall data.

This study is performed on an area located in the northern part of Odisha, a state of eastern India which lies in the sub-tropical region. It is known that the sub-tropical regions are transitioning from tropical regions to temperate regions. However, this region is relatively close to the equatorial warm-climate region. Hence the forecasting model is well developed and can be used for approximate analysis of regions lying on similar latitudes. The development of a similar fuzzy model for temperate regions and subpolar regions especially in the northern hemisphere can be an interesting research problem in the future.

\section{Declarations}

Funding: No funding was received to carry out this research.

Conflicts of interest/Competing interests: There are no potential Conflicts of interest/Competing interests among the authors.

Ethics approval/declarations: This is original research carried out at the Department of Civil Engineering, NIT Rourkela. This manuscript is submitted only to the Theoretical and Applied Climatology and is not under consideration elsewhere. The remaining ethical guidelines as per the journal's website are fulfilled.

Consent to participate: Informed consent was obtained from all individual authors included in the study. Furthermore, I have been assured that any future questions I may have will also be answered by the authors.

Consent for publication: The publisher has the author's permission to publish research findings. With the consent, the author gives the publisher license of the copyright which provides the publisher with the exclusive right to publish and sell the research findings in all languages, in whole or in part.

Author contribution: M.Uma Maheswar Rao: Conceptualization, Data Collection, Data Sorting, and Writing Original Draft. Kanhu Charan Patra: Finalization of Problem, Review of Final Manuscript, Interpretation of Results. Suvendu Kumar Sasmal: Data Analysis, Coding, Writing Original Draft, and Editing.

Availability of data and materials: The data that support the findings of this study are available from the corresponding author (mahesh93.happy@gmail.com) upon reasonable request. 
Code availability: The codes that support the findings of this study are available from the corresponding author (mahesh93.happy@gmail.com).

\section{References}

1. Aftab S, Ahmad M, Hameed $N$ et al (2018) Rainfall prediction in Lahore City using data mining techniques. Int J Adv Comput Sci Appl 9:254-260. https://doi.org/10.14569/IJACSA.2018.090439

2. Aldrian E, Djami YS (2010) Application of Multivariate Anfis for Daily Rainfall Prediction: Influences of Training Data Size. MAKARA Sci Ser 12:7-14. https://doi.org/10.7454/mss.v12i1.320

3. Ashrafı M, Chua LHC, Quek C, Qin X (2017) A fully-online Neuro-Fuzzy model for flow forecasting in basins with limited data. J Hydrol 545:424-435. https://doi.org/10.1016/j.jhydrol.2016.11.057

4. Bacanli UG, Firat M, Dikbas F (2009) Adaptive Neuro-Fuzzy inference system for drought forecasting. Stoch Environ Res Risk Assess 23:1143-1154. https://doi.org/10.1007/s00477-008-0288-5

5. Calp MH (2019) A hybrid ANFIS-GA approach for estimation of regional rainfall amount. Gazi Univ J Sci 32:145-162

6. Del Real AJ, Dorado F, Durán J (2020) Energy demand forecasting using deep learning: Applications for the French grid. Energies 13. https://doi.org/10.3390/en13092242

7. Emamgholizadeh S, Moslemi K, Karami G (2014) Prediction the Groundwater Level of Bastam Plain (Iran) by Artificial Neural Network (ANN) and Adaptive Neuro-Fuzzy Inference System (ANFIS). Water Resour Manag 28:5433-5446. https://doi.org/10.1007/s11269-014-0810-0

8. Indirarani S, Arulalan T, George JP et al (2021) IMDAA: High-resolution satellite-era reanalysis for the indian monsoon region. J Clim 34:5109-5133. https://doi.org/10.1175/JCLI-D-20-0412.1

9. Jang JR (1993) ANFIS: Adap tive-Ne twork-Based Fuzzy Inference System. 23

10. Karaboga D, Kaya E (2019) Adaptive network based fuzzy inference system (ANFIS) training approaches: a comprehensive survey. Artif Intell Rev 52:2263-2293.

https://doi.org/10.1007/s10462-017-9610-2

11. Kişi Ö (2006) Daily pan evaporation modelling using a neuro-fuzzy computing technique. J Hydrol 329:636-646. https://doi.org/10.1016/J.JHYDROL.2006.03.015

12. Kyada PM, Kumar P, Sojitra MA (2018) Rainfall forecasting using Artificial Neural Network (ANN) And Adaptive Neuro-Fuzzy Inference System (ANFIS) models. Int J Agric Sci 10:6153-6159

13. Mekanik F, Imteaz MA, Talei A (2016) Seasonal rainfall forecasting by adaptive network-based fuzzy inference system (ANFIS) using large scale climate signals. Clim Dyn 46:3097-3111. https://doi.org/10.1007/s00382-015-2755-2

14. Mosavi A, Ozturk P, Chau KW (2018) Flood prediction using machine learning models: Literature review. Water (Switzerland) 10:1-40. https://doi.org/10.3390/w10111536

15. Nourani V, Komasi M (2013) A geomorphology-based ANFIS model for multi-station modeling of rainfall-runoff process. J Hydrol 490:41-55. https://doi.org/10.1016/j.jhydrol.2013.03.024 
16. Novitasari DCR, Rohayani H, Suwanto et al (2020) Weather Parameters Forecasting as Variables for Rainfall Prediction using Adaptive Neuro Fuzzy Inference System (ANFIS) and Support Vector Regression (SVR). J Phys Conf Ser 1501. https://doi.org/10.1088/1742-6596/1501/1/012012

17. Rao KK, Kulkarni A, Patwardhan S et al (2020) Future changes in precipitation extremes during northeast monsoon over south peninsular India. Theor Appl Climatol 142:205-217. https://doi.org/10.1007/s00704-020-03308-y

18. Rasel HM, Imteaz MA (2016) Application of Artificial Neural Network for seasonal rainfall forecasting: A case study for South Australia. Lect Notes Eng Comput Sci 2223:130-134

19. Sai Tarun GB, Sriram JV, Sairam K et al (2019) Rainfall prediction using machine learning techniques. Int J Innov Technol Explor Eng 8:957-963

20. Sharma A, Goyal MK (2017) A Comparison of Three Soft Computing Techniques, Bayesian Regression, Support Vector Regression, and Wavelet Regression, for Monthly Rainfall Forecast. J Intell Syst 26:641-655. https://doi.org/10.1515/jisys-2016-0065

21. Suparta W, Samah AA (2020) Rainfall prediction by using ANFIS times series technique in South Tangerang. Indonesia Geod Geodyn 11:411-417. https://doi.org/10.1016/j.geog.2020.08.001

22. Tektas M (2010) Weather forecasting using ANFIS and ARIMA models. Environ Res Eng Manag $51: 5-10$

23. Usha S, Priya SB (2016) An Effective approach for promoting agriculture by predicting rainfall in India by using Machine learning techniques. 37-43

24. Zhang X, Li A, Pan R (2016) Stock trend prediction based on a new status box method and AdaBoost probabilistic support vector machine. Appl Soft Comput J 49:385-398.

https://doi.org/10.1016/j.asoc.2016.08.026

25. Zhang X, Mohanty SN, Parida AK et al (2020) Annual and Non-Monsoon Rainfall Prediction Modelling Using SVR-MLP: An Empirical Study from Odisha. IEEE Access 8:30223-30233. https://doi.org/10.1109/ACCESS.2020.2972435

\section{Figures}




\section{Brahamani Basin Upper Brahamani Basin (Study Area)}

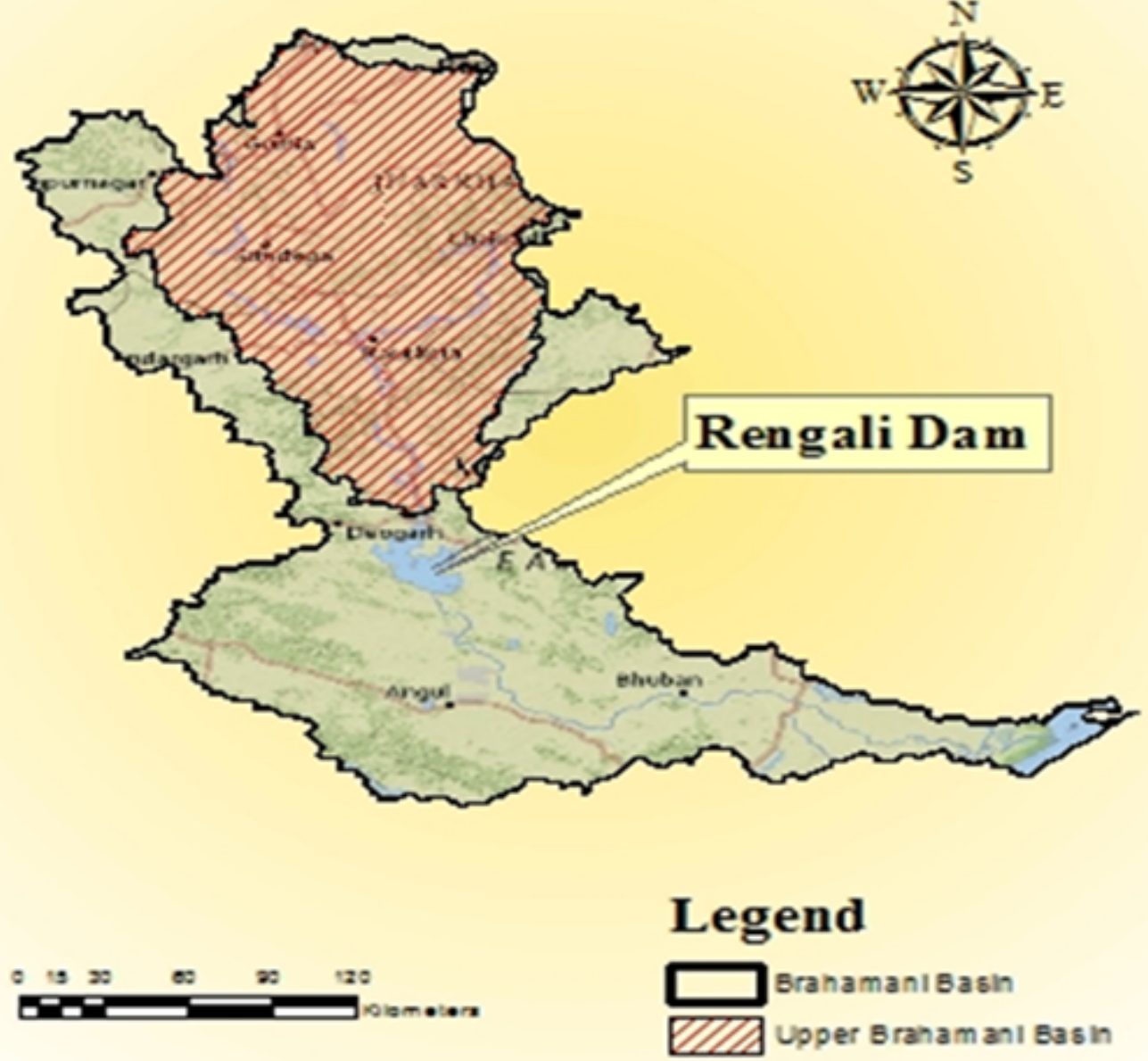

Figure 1

Map of the study area 


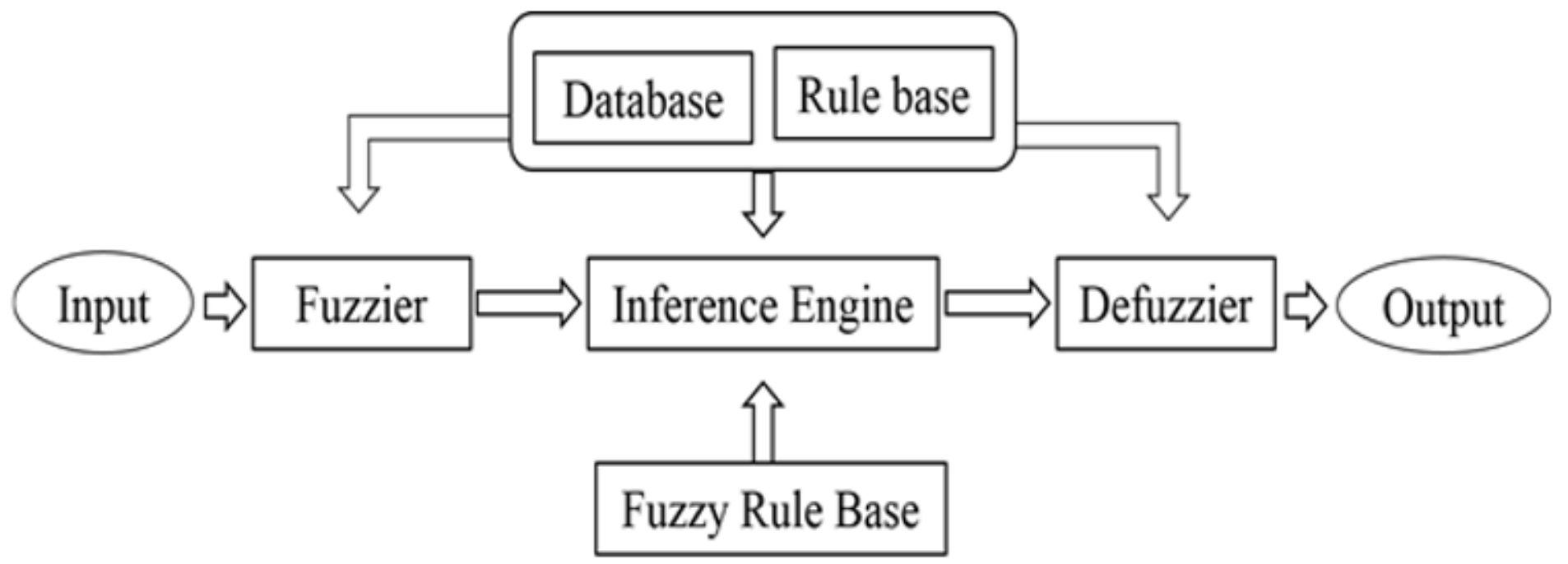

Figure 2

Fuzzy Interface system

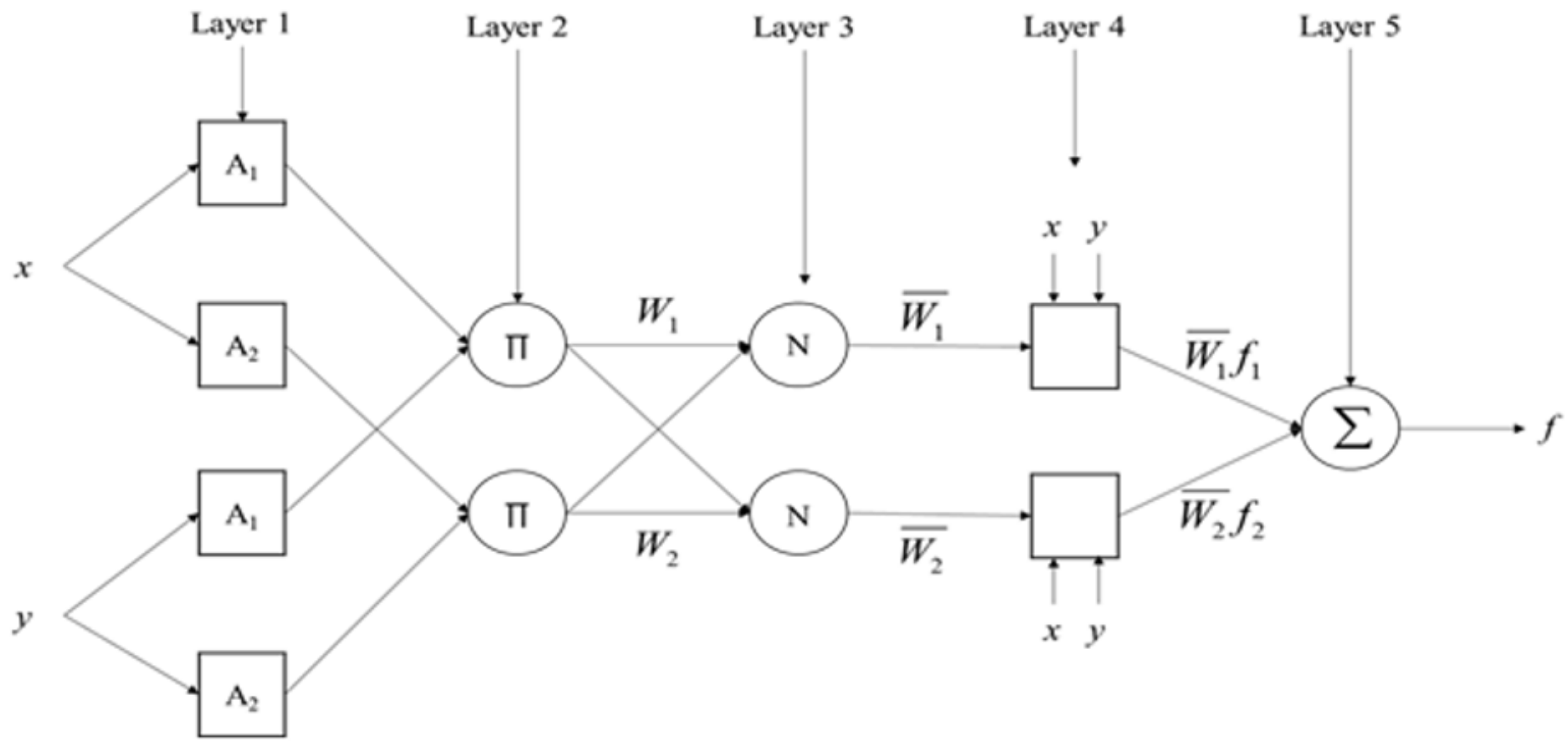

Figure 3

ANFIS architecture (Jang, 1993) 


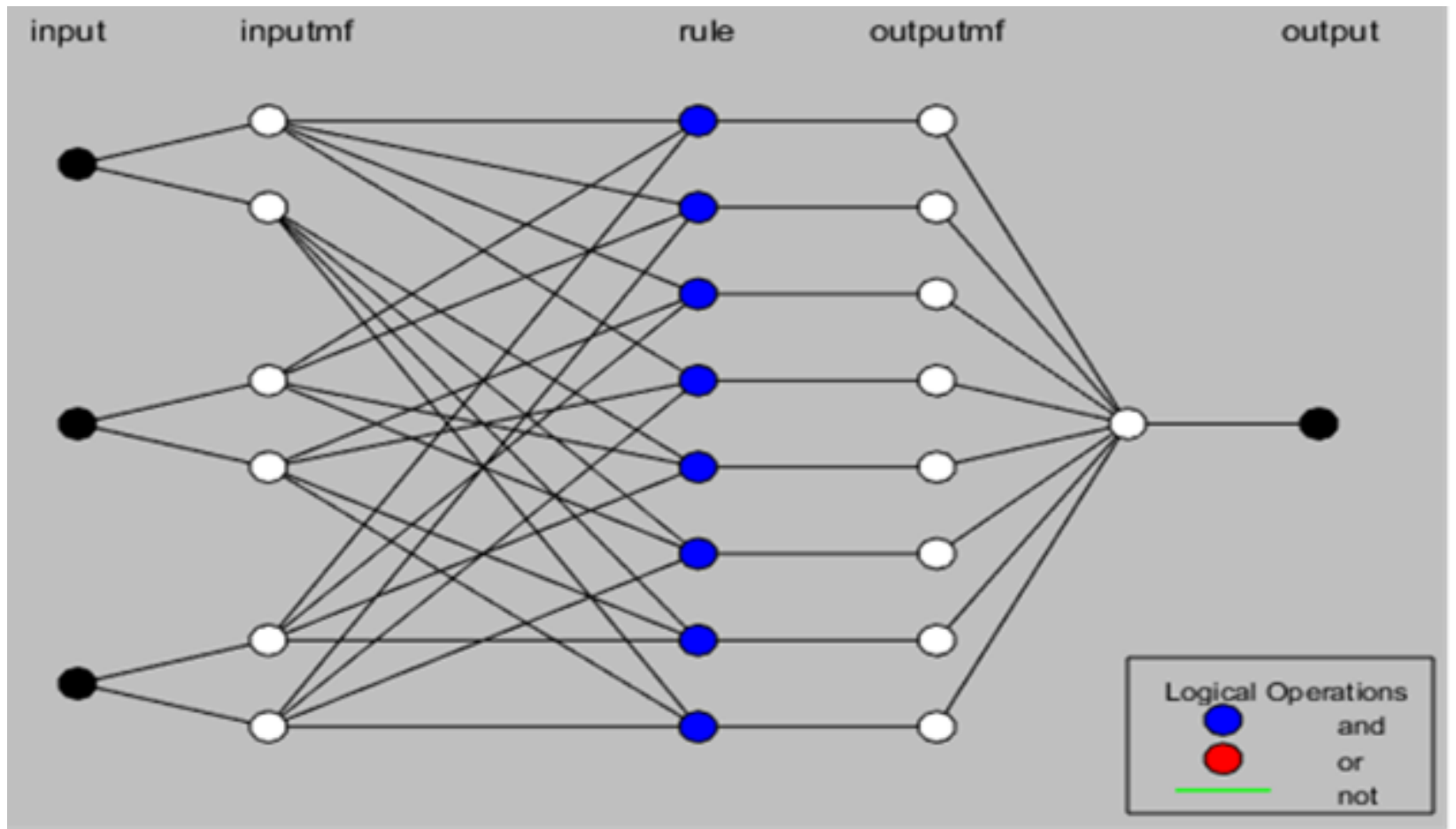

Figure 4

Structure of present ANFIS model

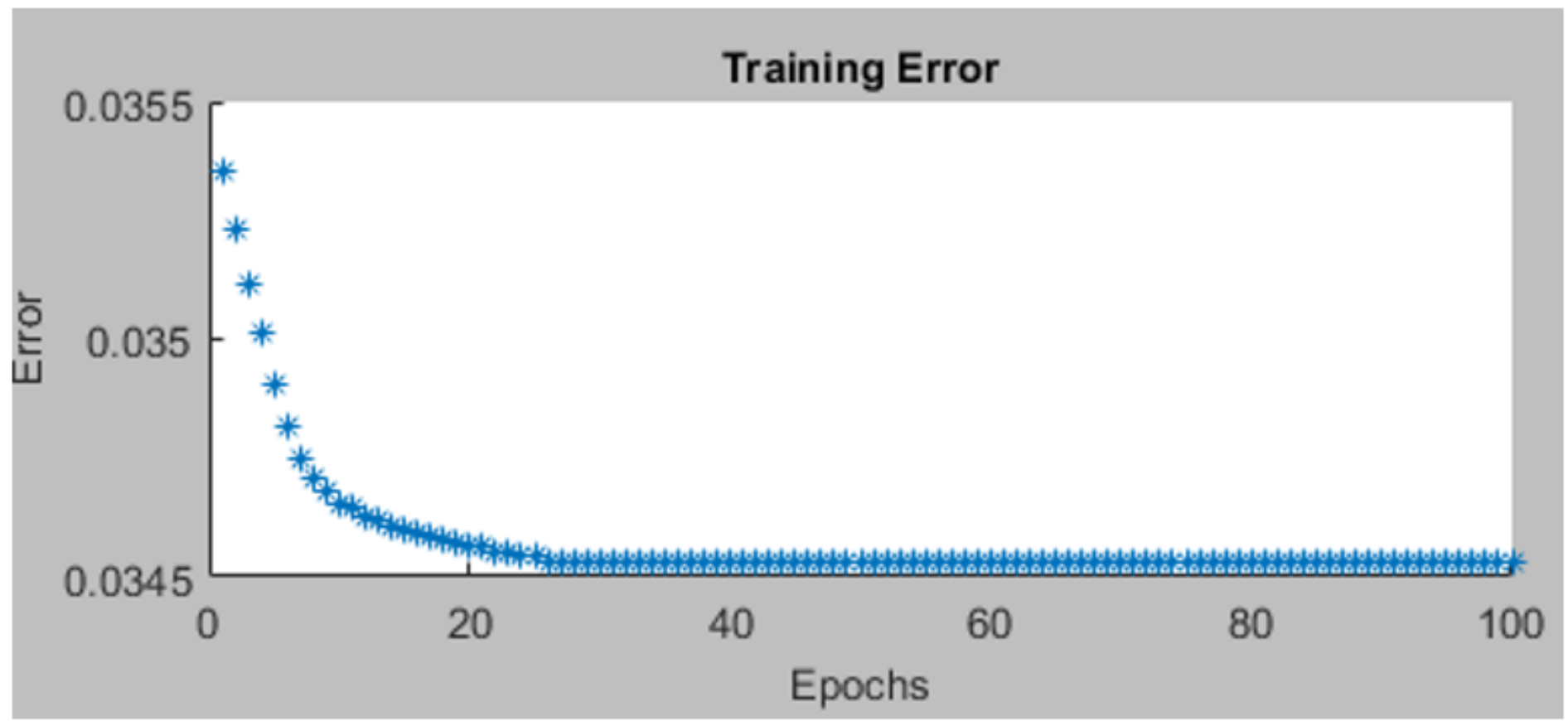

Figure 5

Present training state 


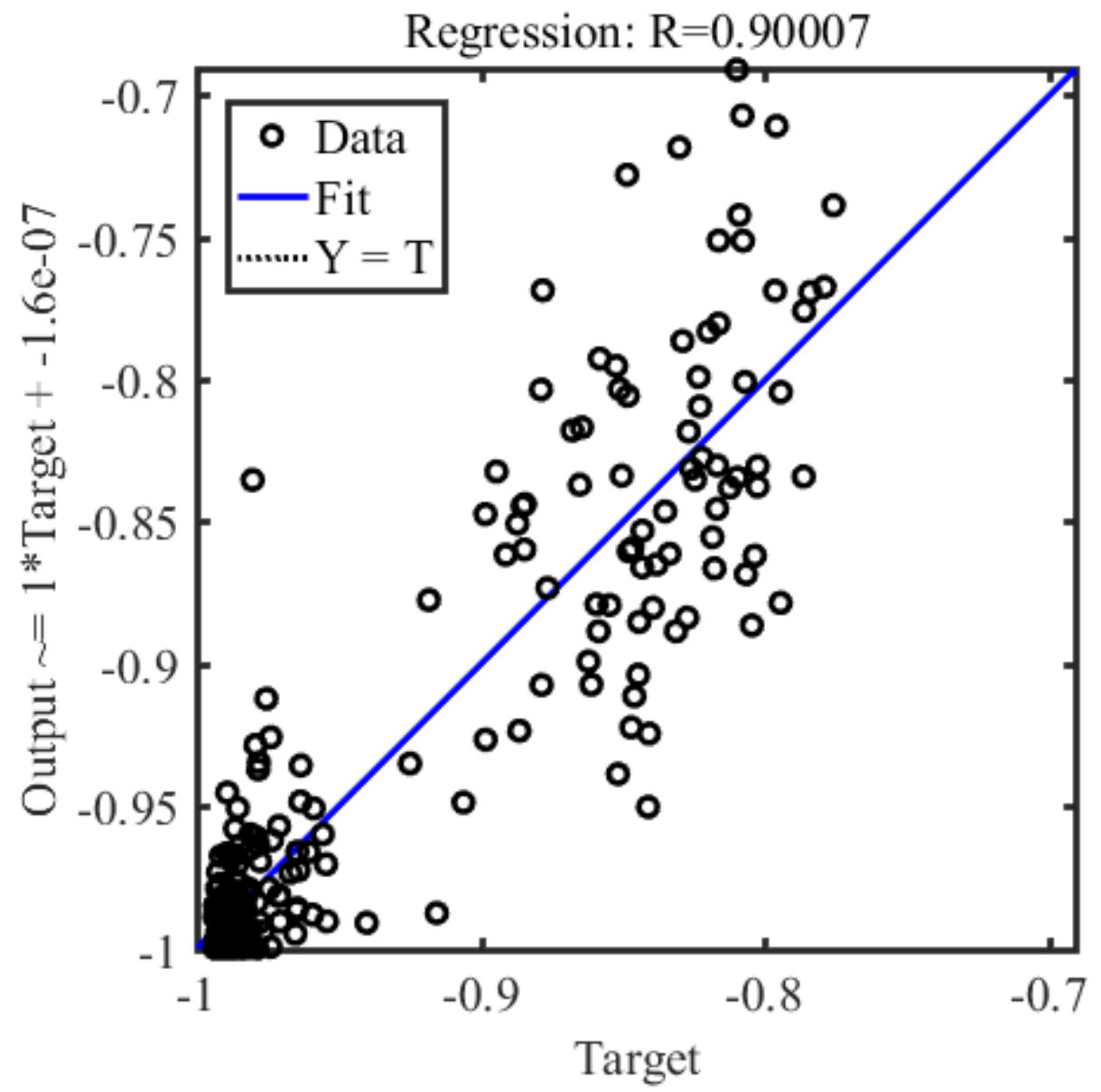

Figure 6

Comparison of ANFIS outcomes with actual data for training data set 


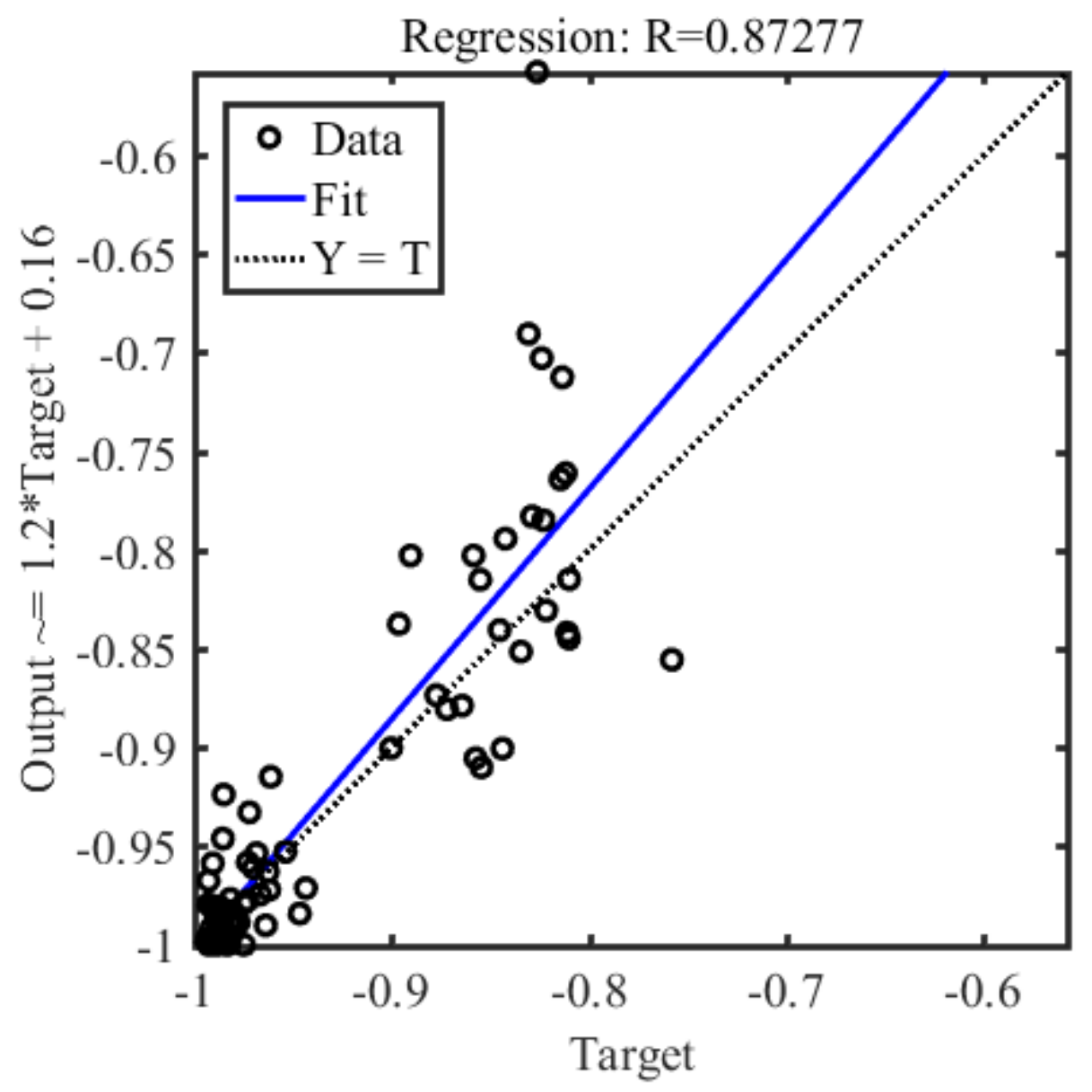

Figure 7

Comparison of ANFIS outcomes with actual data for testing data set 

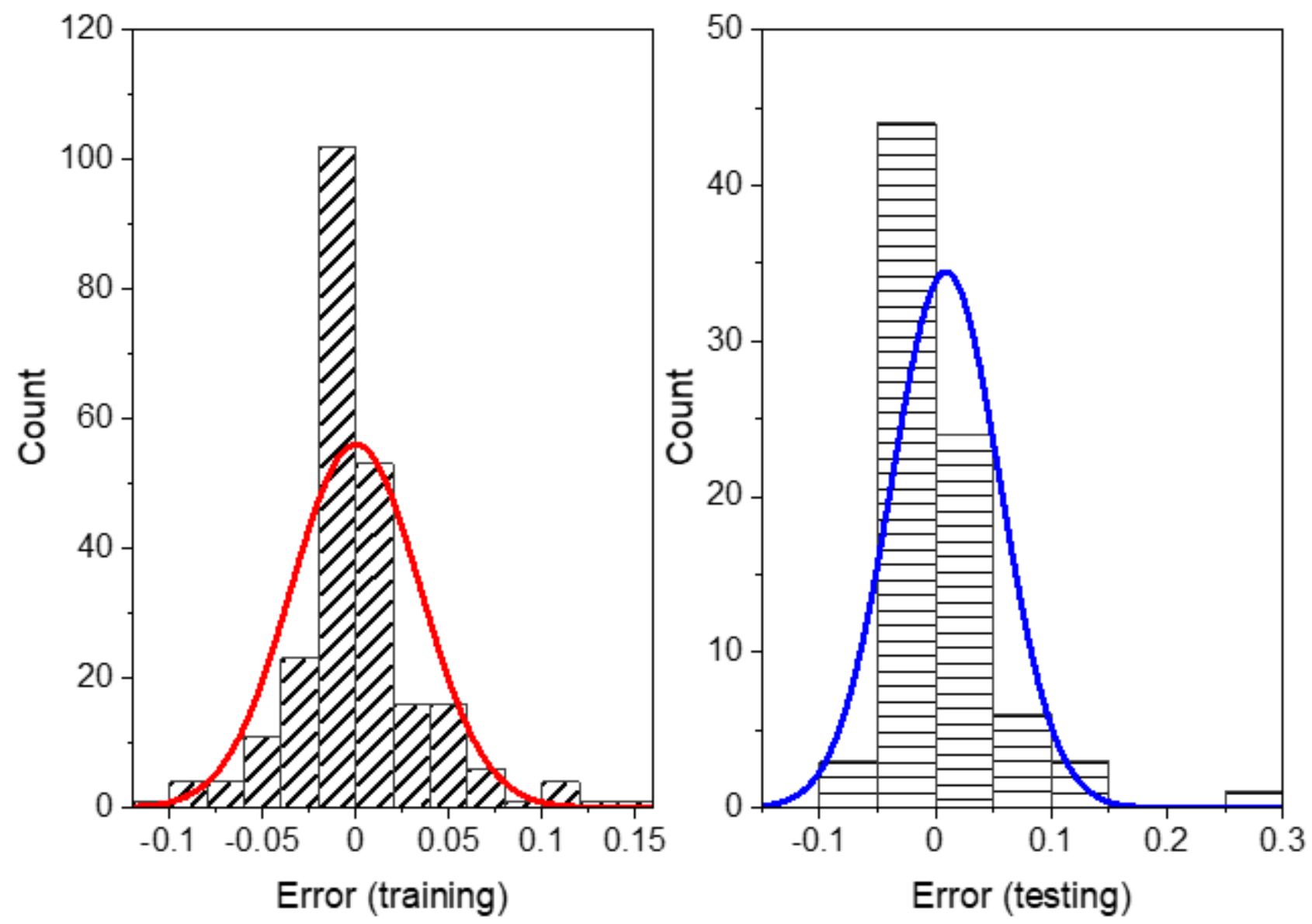

Figure 8

Error distribution for training and testing 


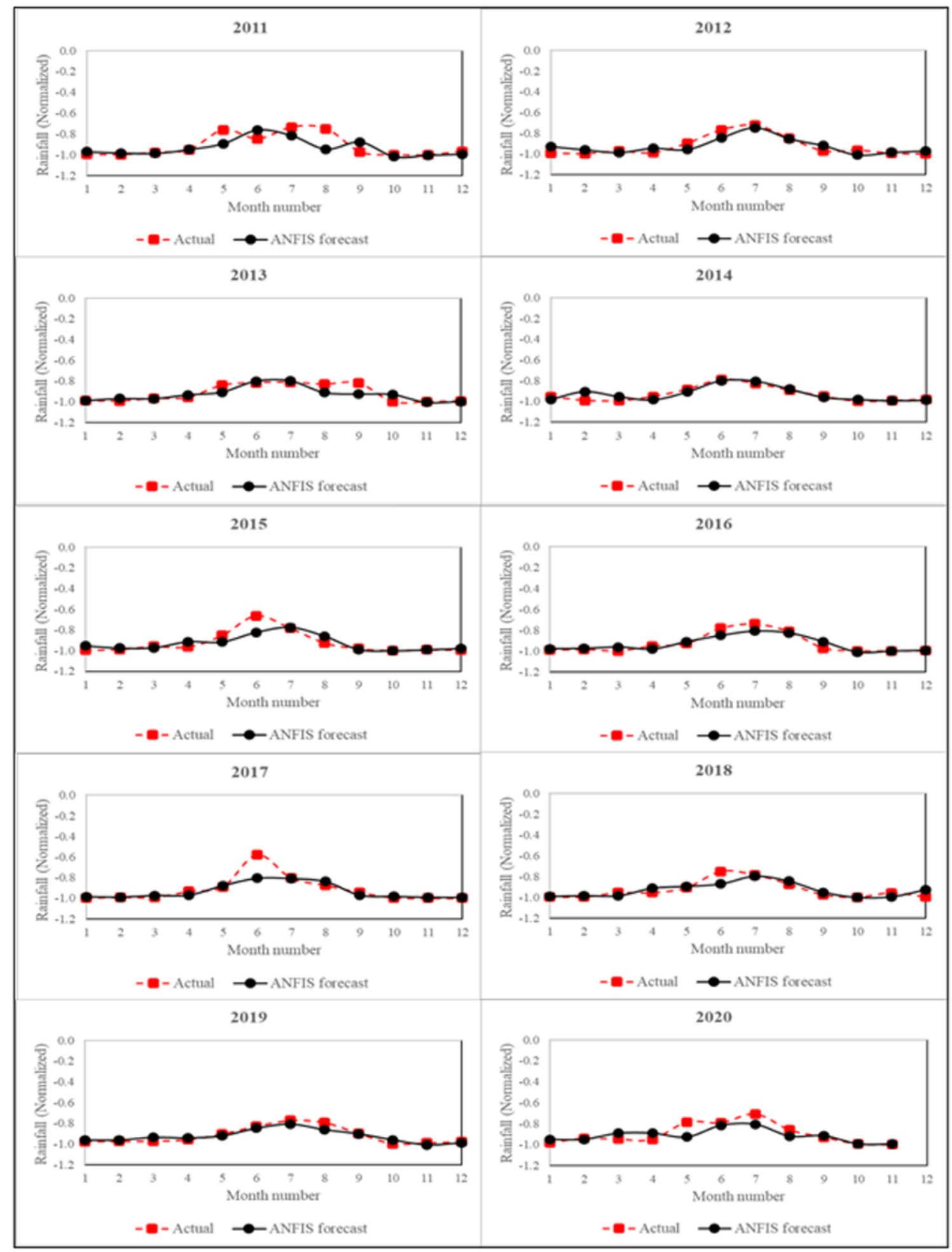

Figure 9

Comparison of forecasted results with actual results for 2011-2020 


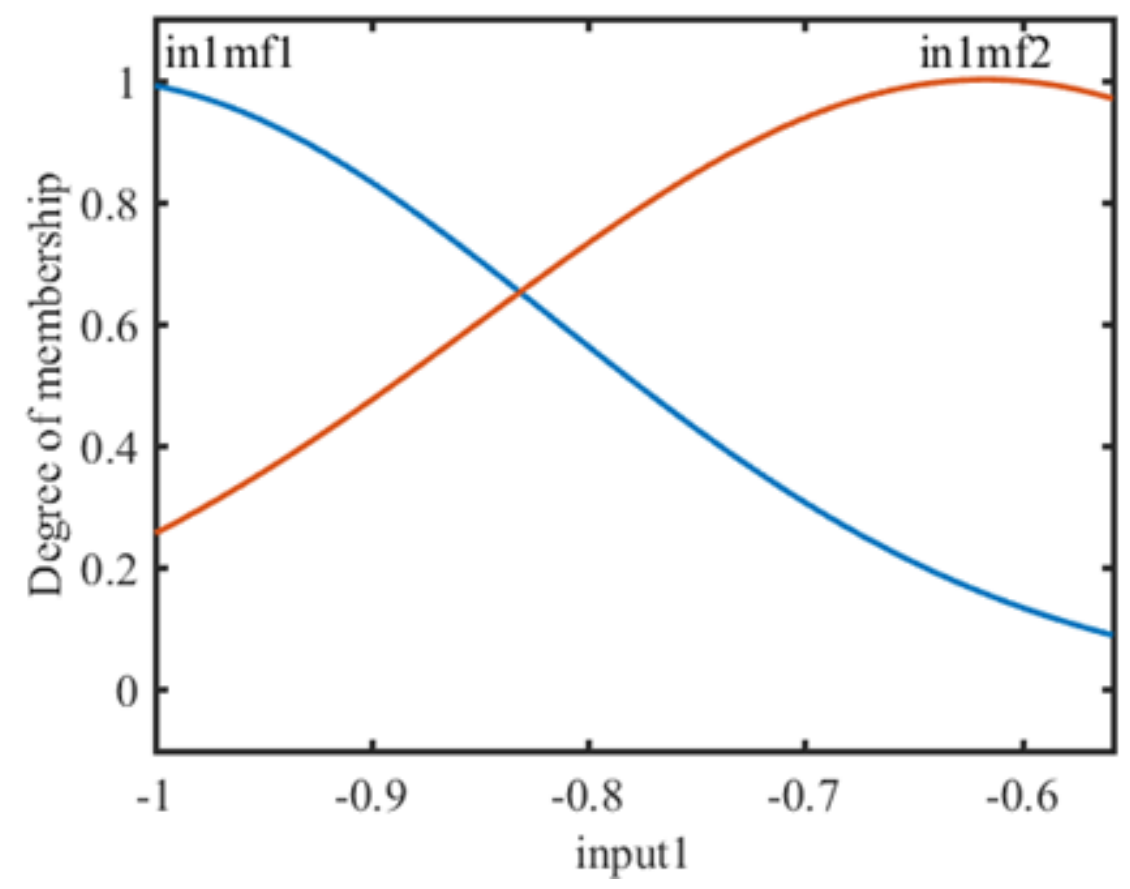

Figure 10

Membership functions for $\mathrm{R}(\mathrm{t})$

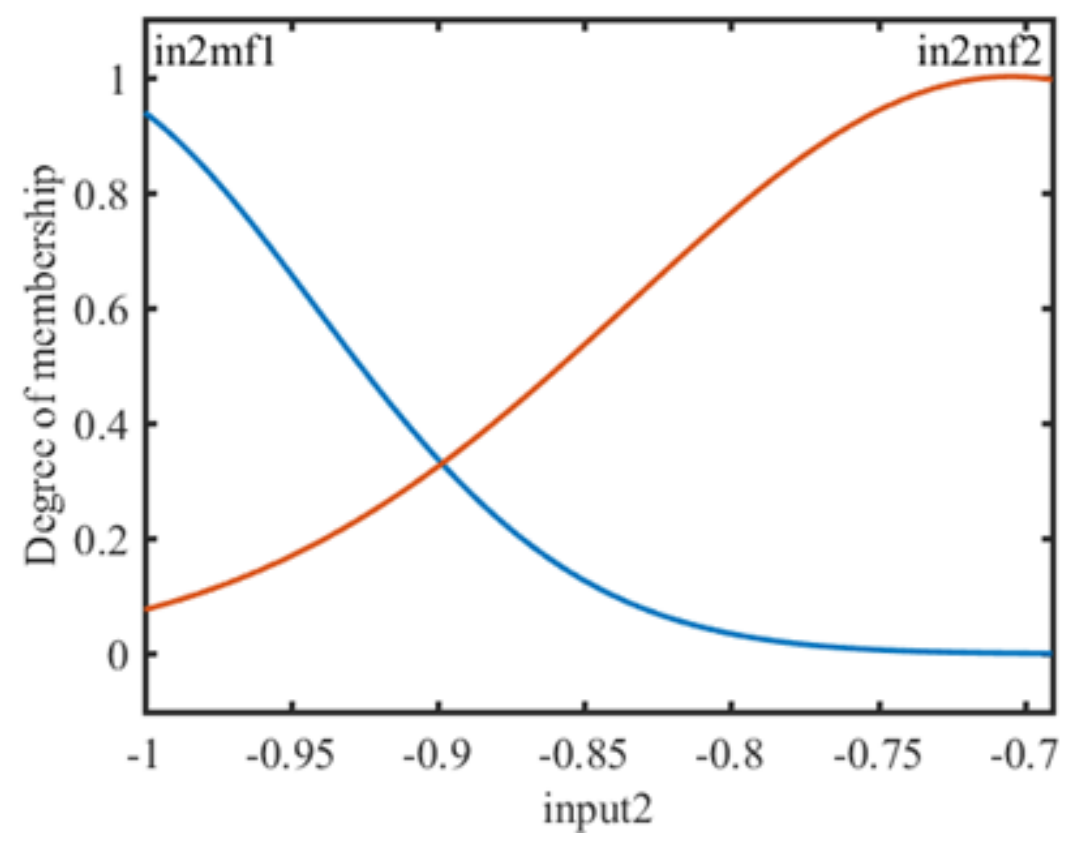

Figure 11

Membership functions for R ( $\mathrm{t}-1)$ 


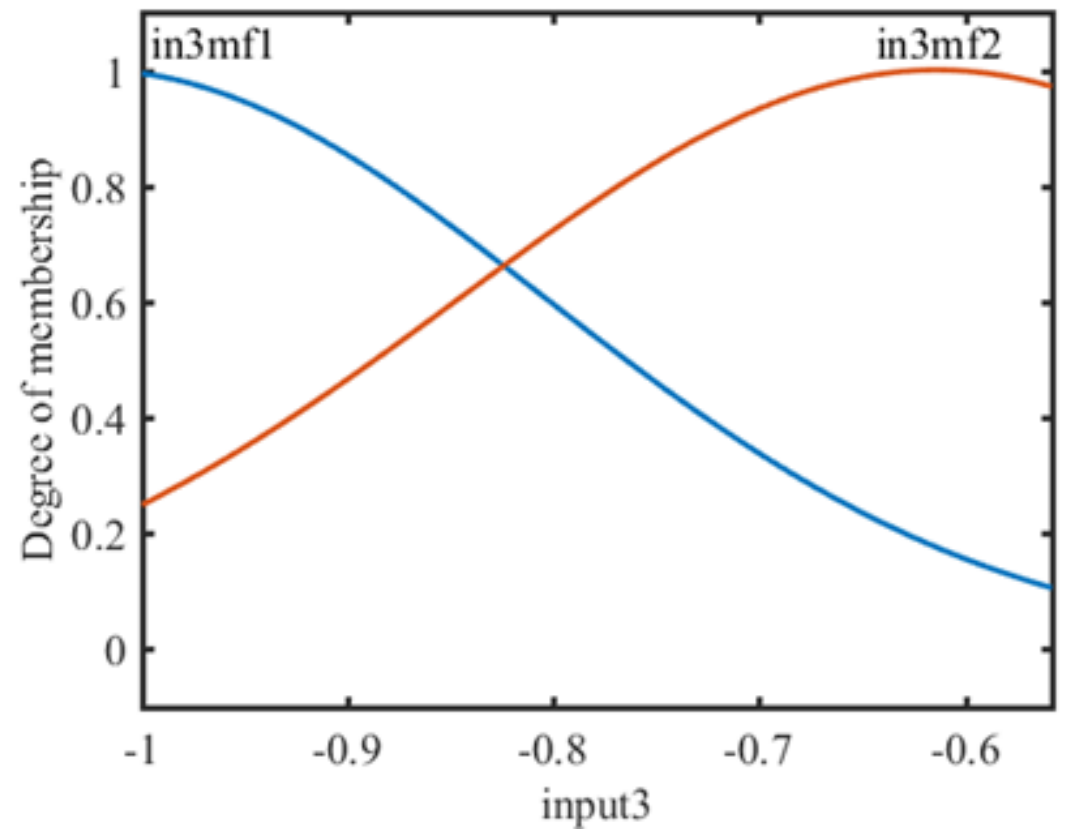

Figure 12

Membership functions for R ( $\mathrm{t}-2$ ) 


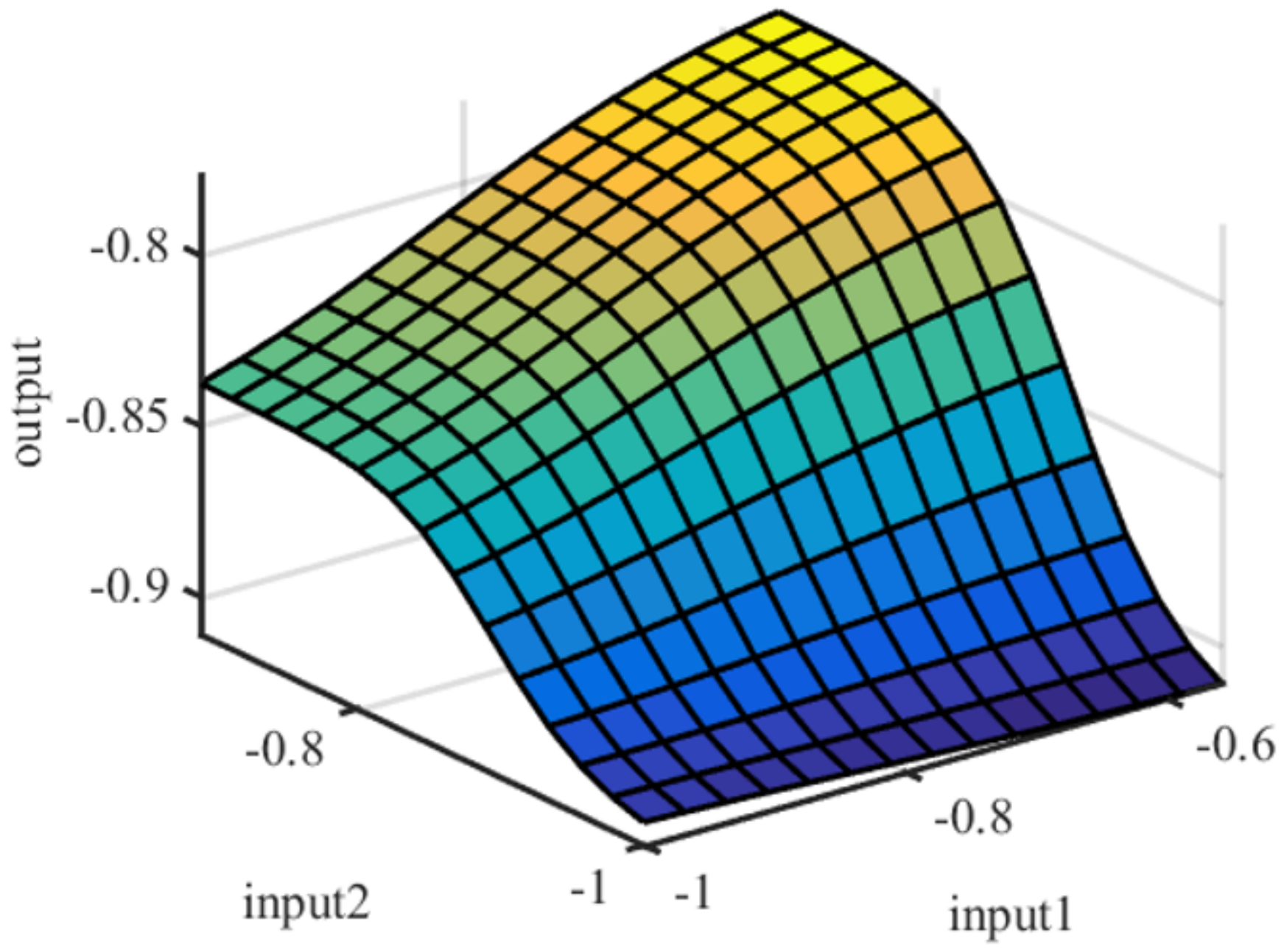

Figure 13

Combined effect of $R(t), R(t-1)$ 


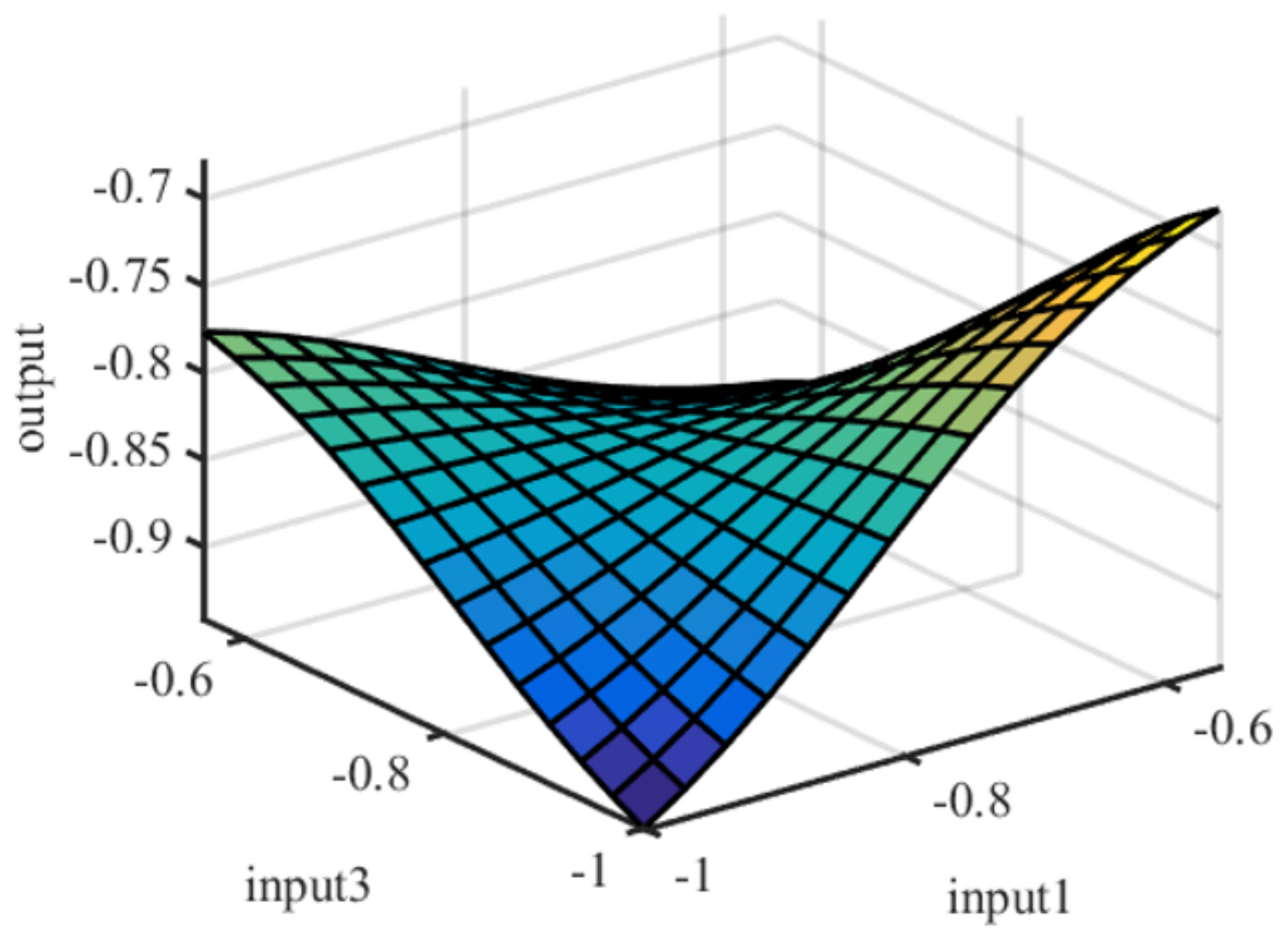

Figure 14

Combined effect of $R(t), R(t-2)$ 


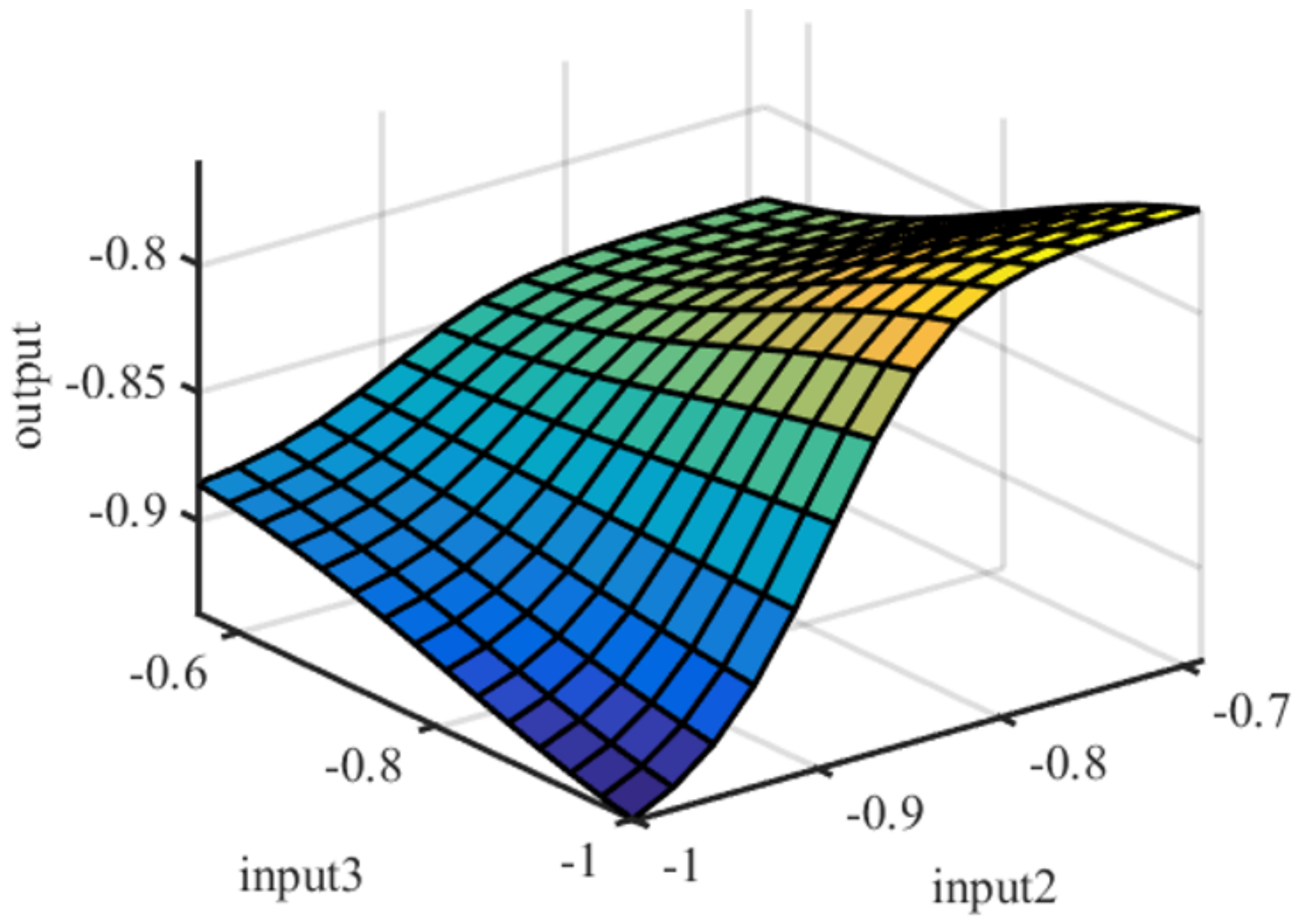

Figure 15

Combined effect of $R(t-1), R(t-2)$ 


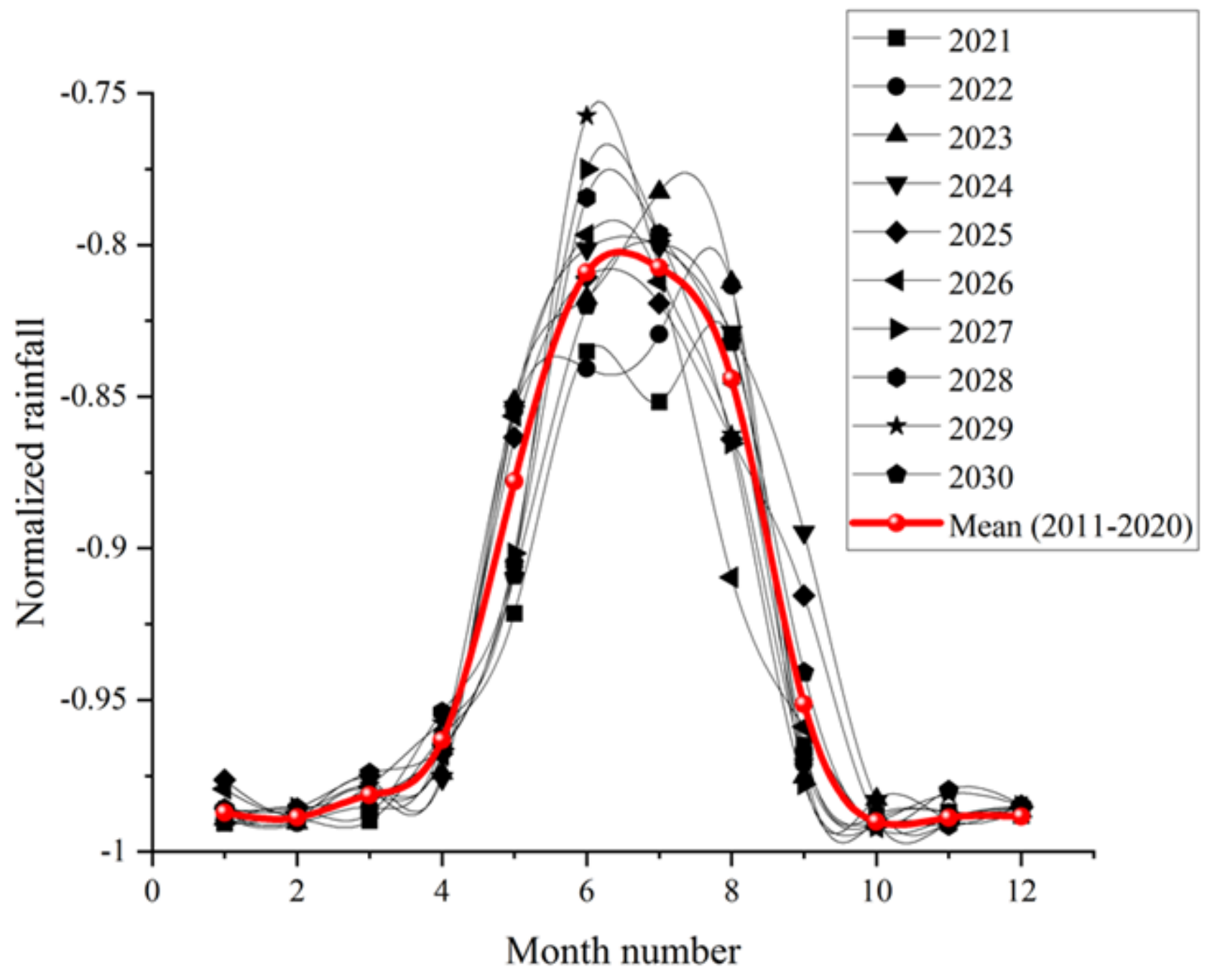

Figure 16

Forecasted Monthly Normalized Rainfall from 2021 to 2030, along with the average rainfall from 2011 to 2020 